\title{
AVALIAÇÃO DE APRENDIZAGEM NOS CONTORNOS DO CURRÍCULO \\ INTEGRADO NO ENSINO MÉDIO
}

\author{
Ilma Ferreira Machado ${ }^{1}$ \\ Rose Márcia da Silva ${ }^{1}$ \\ Maria de Lourdes Jorge de Souza ${ }^{1}$
}

\begin{abstract}
RESUMO: O objetivo deste artigo foi analisar de que forma a avaliaçáo de aprendizagem é proposta para o ensino médio brasileiro, a partir das Diretrizes Curriculares Nacionais do Ensino Médio (DCNEM) e do Pacto Nacional de Fortalecimento do Ensino Médio (PNFEM), atentando para sua articulação com os diversos componentes do currículo integrado. Indagamos sobre as possibilidades de constituir uma nova forma de organização do trabalho pedagógico nas escolas do campo e da cidade, na perspectiva de superação da artificialidade e fragmentaçáo do ensino e da avaliação no ensino médio. Pautamo-nos em uma abordagem crítico-dialética e na metodologia de pesquisa qualitativa, tendo como instrumento a análise dos cadernos do PNFEM e das DCNEM. Com este estudo, esperamos contribuir para a compreensão da função da avaliação no ensino médio, no contexto do currículo integrado e de formação humana integral.
\end{abstract}

Palavras-chave: Avaliação. Pacto Nacional de Fortalecimento do Ensino Médio. Currículo integrado.

\footnotetext{
${ }^{1}$ Universidade do Estado de Mato Grosso, Programa de Pós-graduação em Educação Cáceres (MT), Brasil. E-mail: ilma.ferreiramachado@gmail.com; rose.marcia@oi.com.br; loujorgelb@gmail.com

DOI: $10.1590 / C C 0101-32622016160336$
} 


\title{
Evaluation of learning on the contours of the integrated curriculum in high school
}

\begin{abstract}
The purpose of this article was to analyze how the learning evaluation is proposed for the Brazilian high school, from the National Curriculum Guidelines High School (DCNEM) and the National Pact for the Strengthening of Secondary Education (PNFEM), paying attention to their articulation with the various components of the integrated curriculum. We inquired about the possibilities of establishing a new form of pedagogical organization work in schools from the countryside and the city, with a purpose to overcome the fragmentation and artificiality from process of teaching and evaluation in high school. We are supported in a critical-dialectical perspective and on qualitative research methodology, having as instrument of analysis the PNFEM books and DCNEM. With this study, we hope to contribute to the understanding of the function of evaluation in high school, in the context of the integrated curriculum and integral human formation.
\end{abstract}

Keywords: Evaluation. National Pact for the Strengthening of Secondary Education. Integrated curriculum.

\section{INTRODUÇÃO}

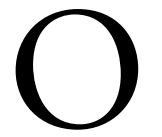

ensino médio no Brasil vem se configurando como um dos principais desafios a serem enfrentados por nossa sociedade. Embora tenhamos obtido melhorias nessa última década, mais de 50\% dos jovens de 15 a 17 anos ainda estáo fora da escola. Fato que levou a se estabelecer como meta do Plano Nacional de Educação, até 2024, a elevação da taxa líquida de matrículas no ensino médio para 85\%. Outro fator preocupante é a inadequação idade-série, assim como as taxas de rendimento - aprovação, reprovação e abandono. Dados de 2012 do Instituto Nacional de Estudos e Pesquisas Educacionais Anísio Teixeira (INEP), vinculado ao Ministério da Educação (MEC), indicam que um em cada quatro jovens matriculados não consegue aprovação no ensino médio (BRASIL, 2013a). 
Moraes e Alavarse (2011) e Kuenzer (2009) apontam como causas do insucesso escolar a inadequação/abstração dos currículos, a não integração entre as disciplinas do núcleo comum e da parte diversificada, a inadequação do processo de avaliação da aprendizagem, a carência de investimentos em termos de infraestrutura e de equipamentos nas escolas e a qualidade da formação dos professores que atuam nessa etapa da educação básica.

Neste artigo buscamos analisar como a avaliação tem sido concebida e articulada nas principais proposiçóes do ensino médio no Brasil, configuradas no Pacto Nacional de Fortalecimento do Ensino Médio (PNFEM), instituído em 2013, e nas Diretrizes Curriculares Nacionais do Ensino Médio (DCNEM) dessa etapa da educação básica.

\section{A AVALIAÇÃO NA TRAJETÓRIA DO ENSINO MÉDIO}

A história do ensino médio está entrelaçada com a história da divisão do trabalho e de classes. Segundo Ramos (2004), a razão de ser do ensino médio desde o início esteve centrada no mercado de trabalho. O processo de formação escolar foi se modificando conforme o sistema de produção nas fábricas e indústrias, preparando uns para ser mão de obra e outros para serem dirigentes.

A divisão do ensino em turmas de acordo com idade e aprendizagem teve início entre os anos 1549 e 1759, com o predomínio da pedagogia tradicional ligada à religiáo e centrada na transmissão de valores. A instrução intelectual priorizava o domínio do aspecto formal-instrumental (ler, escrever, contar) e o aspecto concreto da aprendizagem de um ofício. No conjunto de regras destinadas ao ensino (Ratio Studiorum), destacavam-se regras para professores das classes superiores e das classes inferiores, impulsionadas pelo surgimento da manufatura e divisão do trabalho e de classes, produzindo "trabalhadores especializados" nas classes inferiores e lideranças para classes superiores. A avaliação de ensino, caracterizada pelos exames, ocupava posição central nesse processo formativo. Segundo Romanelli (2010, p. 136), "até o final da década de 1920 [...] imperava o sistema de preparatórios de exames parcelados para ingresso no ensino superior". 
A primeira reforma do ensino secundário ocorreu em 1931, com o Decreto no 21.241 (BRASIL, 1932), estabelecendo que a finalidade desse ensino não havia de ser a matrícula nos cursos superiores mas, pelo contrário, a formação do homem para os grandes setores da atividade nacional. A dualidade escolar fica posta quando se define a divisão do ensino secundário em dois ciclos: um fundamental de cinco anos, de formação básica geral, obrigatório para ingresso no ensino superior, e outro complementar de dois anos, de formação propedêutica, que funcionava como uma especialização para ingressos nas faculdades de Direito, Ciências Médicas e Engenharia, o que o caracterizava uma educação para a elite.

A dualidade escolar é reforçada no Estado Novo, quando se erigiu uma arquitetura educacional que ressaltava a sintonia entre a divisão social do trabalho e a estrutura escolar, isto é, entre o ensino secundário, destinado às "elites condutoras", e os ramos profissionais do ensino médio, destinados às "classes menos favorecidas" (CUNHA, 2005 , p. 7). O processo de avaliação era altamente seletivo, extremamente rígido, exigente e exagerado, o que demandava um alto grau de controle sobre programas e métodos de ensino.

Com a pedagogia nova (1932-1969) e o Manifesto dos Pioneiros, evidenciou-se uma luta para "que a educação se convertesse, de uma vez por todas, num direito" (ROMANELLI, 2010, p. 149), e para concretizar-se como tal deveria estar acima de interesses de classe. A educação passa a ser vista como um problema social. Entre as reivindicaçóes estavam: escola pública e direito de cada indivíduo à educação integral, sob a responsabilidade do Estado. O ensino secundário deveria ter uma base comum de três anos e uma parte diversificada dividida em seção intelectual e seção manual.

As Constituiçóes de 1934 e 1937 representaram uma vitória do movimento renovador, determinando a criação de Plano Nacional de Educaçáo e fixando a educação como direito de todos e dever dos poderes públicos, além da gratuidade do ensino. No entanto, no tocante ao ensino secundário, essa constituição reforçou o ensino dual, destinando o ensino profissional às classes menos favorecidas, "[...] instituindo oficialmente a discriminação social através da escola” (ROMANELLI, 2010, p. 156). 
A partir de 1942, com a Reforma Capanema, modificou-se parcialmente a organizaçáo do ensino, dividindo ensino secundário e ensino técnico profissional. Porém, permanecia a falta de flexibilidade entre o ensino profissional e o ensino secundário, a limitação de acesso ao ensino superior somente nos ramos profissionais correspondentes e a oficialização da seletividade, mediante um processo de avaliaçâo classificatório e excludente.

Novas reestruturaçóes do ensino médio ocorrem entre os anos de 1969 e 2001 em adaptação ao modelo produtivista em desenvolvimento, centrando-se primeiramente na pedagogia tecnicista, depois na pedagogia crítico-social dos conteúdos e finalmente na pedagogia das competências e da qualidade total. A avaliação, na Lei no 5.692 (BRASIL, 1971), que estava pautada em princípios tecnicistas, era concebida como medição e verificação do rendimento do aluno, conforme podemos observar no artigo 14: "a verificação do rendimento escolar ficará [...] a cargo dos estabelecimentos, compreendendo a avaliação do aproveitamento e a apuração da assiduidade". Essa situação remete ao pensamento de Enguita (1989, p. 189), quando destaca que a escola no âmbito da sociedade capitalista sanciona "traços de caráter e formas de conduta funcionais" para o trabalho assalariado, tais como: controle do tempo, submissão à autoridade, rejeição da criatividade e da autonomia dos sujeitos.

A pedagogia das competências surge no contexto da Conferência Mundial de Educação para Todos, ocorrida em 1990, que traçou como prioridade "a redução das taxas de analfabetismo e a universalização do ensino básico" e definiu como necessidades básicas de aprendizagem: conhecimentos, habilidades, valores e atitudes necessários para "sobreviver, desenvolver plenamente suas potencialidades, viver e trabalhar com dignidade, participar plenamente do desenvolvimento, melhorar a qualidade de vida, tomar decisóes fundamentais e continuar aprendendo" (SILVA, 2008, p. 108-109). Os fundamentos dessa reforma podem ser encontrados na teoria psicogenética de Piaget, que "evidencia o uso da ideia de competência cognitiva, quando se trata, principalmente, de propor formas de avaliação dos resultados do ensino médio" e na teoria da sintaxe de Chomsky "quando propóe a avaliação a partir de uma matriz de competência estruturada com base no desempenho" (SILVA, 2008, p. 14). 
Competências são as modalidades estruturais da inteligência, ou melhor, açóes e operaçóes que utilizamos para estabelecer relaçóes com e entre objetos, situaçóes, fenômenos e pessoas que desejamos conhecer. As habilidades decorrem das competências adquiridas e referem-se ao plano imediato do "saber fazer". Através das açóes e operaçóes as habilidades aperfeiçoam-se e articulamse, possibilitando nova reorganização das competências (BRASIL, 2000, p. 7).

Para Silva (2008, p. 110), esse modelo culminou com o Plano Decenal de Educação 1993-2003, apontando como uma das finalidades da escola o provimento de "competências fundamentais requeridas para plena participação na vida econômica, social, política e cultural do País", atrelando o modelo de competências à lógica posta pela economia e pelo mercado de trabalho. Em decorrência das avaliações externas do Sistema de Avaliação da Educação Básica e, posteriormente, do Exame Nacional do Ensino Médio, a partir de 1998, foram definidos os Parâmetros Curriculares Nacionais e as Diretrizes Curriculares Nacionais (1998), gerando novos discursos sobre currículo, avaliação e práticas pedagógicas.

As prescrições normativas para o currículo do ensino médio justificaram-se como medida necessária para adaptar a escola às mudanças ocorridas na sociedade e no mundo do trabalho, mas o que se evidenciou foi o caráter de adaptação da formaçáo às demandas do mercado de trabalho. As referências às mudanças no mundo do trabalho, nos textos oficiais, restringiram-se às inovaçóes tecnológicas e organizacionais, ignorando "o trabalho como uma prática humana que assume, nessa formação econômica, a condição de trabalho alienado, de mercadoria” (SILVA, 2008, p. 18). A formação humana na sociedade capitalista

[...] tem sido remetida predominantemente à formação para o trabalho, e este, na sua forma mercadoria, circunscreve processos que conduzem a uma semiformação cultural, uma vez que impóe limites à condução do homem para a autorreflexão crítica (SILVA, 2008, p. 24-25). 
Nesse contexto, os discursos sobre a avaliação de ensino, embora propugnem a crítica, participação e autonomia dos sujeitos da escola, acabam enfatizando os domínios técnicos e cognitivos, em detrimento da formação integral dos adolescentes e jovens do ensino médio.

\section{DIRETRIZES CURRICULARES NACIONAIS DO ENSINO MÉDIO E PACTO NACIONAL DE FORTALECIMENTO DO ENSINO MÉDIO: POSSIBILIDADES DE RECONFIGURAÇÃO DA AVALIAÇÃO?}

Como contraponto ao projeto educativo do capital, desencadeia-se a luta de educadores, de perspectiva socialista, por um projeto de ensino médio que integra formação técnica e formação geral, como sugerido por Manacorda (2010, p. 313), assumindo nova concepção “da relação instrução-trabalho [...] que vai além do somatório de uma instrução tradicional mais uma capacidade profissional e tende a propor a formação de um homem onilateral".

Nessa perspectiva, nos últimos dez anos vêm sendo implementadas políticas curriculares no sentido de fortalecimento do ensino médio e da inter-relação educação e trabalho, tais como as Diretrizes Curriculares Nacionais para a Educação Básica (Resolução no 4, BRASIL, 2010), Diretrizes Curriculares Nacionais para o Ensino Médio (Resolução no 2, BRASIL, 2012a), Diretrizes Curriculares Nacionais para a Educação Profissional Técnica de Nível Médio (Resolução no 6, BRASIL, 2012b) e o Pacto Nacional de Fortalecimento do Ensino Médio (BRASIL, 2014).

A vinculação entre educação escolar, trabalho e práticas sociais é trazida como princípio desde a educação básica, como direito universal, conforme artigo 5 da Resolução no 4 (BRASIL, 2010). E as DCNEM trazem, no artigo $4^{\circ}$, entre as finalidades da educação, a consolidação e o aprofundamento dos conhecimentos adquiridos no ensino fundamental; o aprimoramento do educando como pessoa humana e a compreensáo dos fundamentos científico-tecnológicos dos processos produtivos, relacionando teoria e prática.

O ensino médio, conforme a política curricular vigente, independentemente de sua modalidade, deve basear-se na "formação integral 
do estudante", integrando conhecimentos gerais e técnico-profissionais, bem como a educação e as dimensóes do trabalho, da ciência, da tecnologia e da cultura como eixo articulador e estruturante do currículo, entendido como "[...] a proposta de ação educativa constituída pela seleção de conhecimentos construídos pela sociedade" (BRASIL, 2012a, p. 2) e orientado por metodologias de ensino e avaliaçáo que promovam a autonomia e a iniciativa dos estudantes. O Projeto Político Pedagógico (PPP) da escola deve considerar "[...] a avaliação da aprendizagem, com diagnóstico preliminar, e entendida como processo de caráter formativo, permanente e cumulativo" (BRASIL, 2012a, p. 7).

O objetivo geral do PNFEM ${ }^{1}$ é “[...] formar em nível de aperfeiçoamento ou extensão todos os professores e coordenadores pedagógicos que atuam no Ensino Médio [...] a partir do diálogo entre conhecimentos teóricos e experiências docentes e de gestão pedagógica (BRASIL, 2014, p. 4-5). O programa, em seus pressupostos teóricometodológicos, toma o trabalho como princípio educativo e a pesquisa como princípio pedagógico e faz opção pelo diálogo centrado no tripé conhecimentos teóricos, experiências docentes e gestão pedagógica.

De maneira explícita, encontram-se no material impresso os fundamentos da pedagogia histórico-crítica e as teorias críticas do currículo (BRASIL, 2013a). O programa foi elaborado em observância às DCNEM, projetando o fortalecimento do ensino médio, no sentido quantitativo e qualitativo, o que inclui aporte de recursos financeiros e materiais e a melhoria do ensino. Traz avanços importantes ao ter como elemento central a formação humana integral, mediante um currículo integrado assentado nos eixos articuladores trabalho, ciência, tecnologia e cultura (FILHO, 2014 apud RIBEIRO; PÁTARO, 2014, p. 10).

A temática central do programa é "Sujeitos do Ensino Médio e Formação Humana Integral”, e os eixos articuladores são trabalho, ciência, tecnologia e cultura. Foi organizado em 11 cadernos e dividido em 2 etapas. A primeira etapa constituiu-se de seis cadernos de estudos, abrangendo os temas: ensino médio e formação humana integral; o jovem como sujeito do ensino médio; o currículo do ensino médio, seus sujeitos e o desafio da formação humana integral; áreas de conhecimento e a integração curricular; organização e gestão pedagógica da 
escola; avaliação no ensino médio. A segunda etapa contou com cinco cadernos: organização do trabalho pedagógico e as quatro grandes áreas do conhecimento. Nessa etapa realizou-se a articulação entre as áreas do conhecimento, o desenho curricular das DCNEM e dos direitos à aprendizagem e de desenvolvimento para todos os educandos.

$\mathrm{O}$ pacto reconhece o papel do professor como produtor e articulador de conhecimentos, considerando-o "[...] como um sujeito epistêmico, que elabora e produz conhecimentos com base na compreensão da realidade e nas possibilidades de transformação da sociedade" (BRASIL, 2014, p. 5). Por isso, a metodologia da formação continuada está delineada de forma que valorize a participação e a iniciativa do professor. Os tempos curriculares foram organizados em dois momentos distintos. No primeiro momento o professor, individualmente, realiza a leitura dos textos básicos do curso, desenvolve, em sua sala de aula, ao menos uma das atividades propostas no material de estudo e faz o registro das reflexóes realizadas durante as leituras para, posteriormente, socializá-las com o grupo na escola. Todo esse processo prevê a orientação e o acompanhamento pelo orientador de estudo. O segundo momento é reservado às atividades coletivas: na hora-atividade o grupo realiza o estudo das DCNEM, dos textos sobre os campos temáticos e sobre áreas de conhecimento e seus componentes curriculares.

Evidencia-se no documento do pacto uma preocupação em compreender quem são os sujeitos do ensino médio. Esse é um aspecto significativo que tem sido abordado por Dayrell (2005), Spósito (2010), Castro (2009), Krawczyk (2011), entre outros. Constata-se também uma preocupação em efetivar uma educação na perspectiva da formação humana integral. Cabe nos indagar: o que seria necessário para fortalecer o ensino médio e assegurar que os jovens consigam completar o percurso e ter uma formação ampla e qualitativa? Segundo Filho (2014 apud RIBEIRO; PÁTARO, 2014, p. 12), “[...] esse é um dos desafios, que envolve simultaneamente quantidade de vagas e qualidade no ensino a que esses alunos e alunas têm acesso", tanto na cidade, quanto no campo.

Se nos centros urbanos o acesso e a permanência dos jovens no ensino médio é questão desafiadora, mais desafiadora ainda o é nas áreas rurais, cuja oferta precisa ser capitalizada: 
Hoje, cerca de $86 \%$ das escolas de Ensino Médio são urbanas e cerca de $35 \%$ das matrículas estão localizadas no período noturno. É importante aumentar a quantidade de escolas na zona rural e pensar na problemática do ensino noturno. Uma grande parcela da população jovem brasileira que frequenta o Ensino Médio também trabalha [...] (FILHO, 2014 apud RIBEIRO; PÁTARO, 2014, p. 12).

O autor pontuou uma série de questóes que têm implicaçóes para o fortalecimento do ensino médio, porém, não destacou as desigualdades sociais, econômicas e as diversidades culturais.

Conforme consta no Caderno VI, a avaliação é compreendida como componente indissociável do projeto político-pedagógico e do currículo da escola, servindo de apoio ao currículo e ao trabalho docente quando cumpre a função de diagnosticar e fornecer informaçóes sobre o desenvolvimento do aluno. Por sua dimensão formativa, a avaliação acompanha e informa o aluno sobre seu desempenho, a partir de critérios claros e coerentes com o objeto a ser avaliado, devendo estar "a serviço de seu sucesso e não para puni-lo" (BRASIL, 2013b, p. 20).

No pacto, a avaliação não se constitui em etapa final e isolada do processo pedagógico, mas é um elemento articulado ao currículo e às dimensóes estruturais internas e externas à escola, de modo que sobre ela não recaia toda a responsabilidade pelo sucesso ou insucesso escolar do estudante, que é considerado como sujeito do processo de aprendizagem. $\mathrm{O}$ aluno deve ter papel ativo no processo de avaliação e participar da discussão dos critérios avaliativos, de modo que "não sejam vistos como mera idiossincrasia docente" (BRASIL, 2013b, p. 22). Argumentamos que, para além desse cuidado ético, há que se pensar na participação do aluno na condição de auto-organização do coletivo juvenil (PISTRAK, 2001) como mecanismo de democratização das relaçóes de poder no interior da escola e de consolidação de um projeto pedagógico coletivo.

Os cadernos do pacto não explicitam de que forma a avaliação pode ser redimensionada no contexto de um currículo que tem trabalho, cultura, ciência e tecnologia como eixos estruturantes. Na discussão sobre organização do trabalho pedagógico, essa questão também não está 
configurada, o que pode ser decorrente da dificuldade que temos encontrado para materializar, no plano de uma sociedade capitalista, uma proposta que é antagônica à lógica posta. Aliado a isso, estão as condiçóes estruturais de funcionamento do ensino médio, que interferem sobremaneira na realização de um trabalho coletivo e autônomo por parte dos profissionais que atuam nesse nível de ensino, assim como a necessidade de conhecimentos mais aprofundados sobre tais temáticas.

Esse aspecto merece destaque porque tem a ver com a mudança da prática pedagógica e do currículo na perspectiva de concretização do projeto educativo almejado. De modo especial, cabe destacar que na escola articulada à vida e ao trabalho, a superficializaçáo do ensino dá lugar à compreensão teórico-prática dos fenômenos sociais e naturais da realidade na qual os sujeitos se situam, permitindo estabelecer as relaçóes entre o conteúdo das diferentes ciências e a realidade problematizada. Da mesma forma, que a avaliação de aprendizagem não fica restrita à prova ou outro instrumento que cobra apreensão dos conteúdos e o estrito domínio cognitivo com vistas à promoção do estudante em níveis ou séries, ou seja: "[...] avaliar é um processo em que realizar provas e testes, atribuir notas ou conceitos, é apenas parte do todo" (FERNANDES; FREITAS, 2008, p. 19).

A avaliação é uma atividade orientada para o futuro. Avalia-se para tentar manter ou melhorar nossa atuação futura. Essa é a base da distinção entre medir e avaliar. Medir refere-se ao presente e ao passado e visa obter informaçóes a respeito do progresso efetuado pelos estudantes. Avaliar refere-se à reflexão sobre as informaçôes obtidas com vistas a planejar o futuro (FERNANDES; FREITAS, 2008, p. 19).

A avaliação de aprendizagem manifesta-se como mecanismo de diagnóstico, registro, análise e acompanhamento das aprendizagens, portanto, extrapola a classificaçáo dos alunos em aprovados e não aprovados e visa promover a aprendizagem e a formaçáo integral dos jovens. Isso implica em caracterizar como a organização do trabalho pedagógico vem sendo pensada no ensino médio, no sentido de se instituir uma nova cultura da 
avaliação, que possa destituí-la de sua condição finalística e independente e reposicioná-la como elemento integrador e integrante da organizaçáo do trabalho pedagógico no âmbito de um arranjo organizacional favorável à promoção do humano. Esse aspecto parece carecer de melhor discussão no âmbito do PNFEM, a despeito da concepção crítica de avaliação assumida que, sem sombra de dúvida, é algo relevante e coerente com o conceito alargado de educação como processo de formação humana.

Há que se pensar, portanto, no redimensionamento do ensino e da avaliação na direção apontada por Pistrak (2001, p. 96), em que o estudante do ensino médio constitua seu plano de estudo como projeto de vida, assim "o aluno dedica todo o seu tempo exclusivamente à prática e ao projeto que deve executar, tendo por base as questóes da realidade atual e do trabalho". E isso exige a prática da auto-organização do coletivo estudantil na perspectiva de uma "democracia revolucionária" em que os jovens tenham liberdade e iniciativa para organizar suas vidas e participar da organizaçáo da escola como parte de seu projeto de vida e não algo alheio a ele.

\section{CONSIDERAÇÕES FINAIS}

Historicamente, a educação escolar no Brasil tem sido marcada pelo processo de exclusão da classe trabalhadora. Uma das formas de exclusão é caracterizada pela dualidade do ensino médio (FRIGOTTO; CIAVATTA; RAMOS, 2005; KUENZER, 2009) e um dos mecanismos que tem servido para isso é a avaliaçáo. Nas diversas propostas de ensino médio é possível apreender que a avaliação desponta como um poderoso dispositivo de controle do processo ensino-aprendizagem e que, muitas vezes, é vista como categoria que possui uma finalidade em si mesma e que tem como único objetivo apresentar os resultados de aprovação e não aprovação dos estudantes.

O ensino médio centrado na articulação entre trabalho, ciência, tecnologia e cultura, que toma o trabalho como princípio educativo e a pesquisa como princípio pedagógico, se apresenta como um paradigma recente na história da educação brasileira. Ao tempo que se discute a reinvenção do ensino médio, o processo requer muita atenção para as 
questóes da avaliação das aprendizagens. Cabe colocar o processo avaliativo no centro do debate do grupo de educadores da escola e alinhá-lo à organização do trabalho pedagógico, ao currículo e à perspectiva da formação omnilateral, de modo que evite a dissonância entre currículo proclamado/vivenciado e os propósitos teórico-práticos da avaliação realizada com os sujeitos do processo educativo, principalmente os estudantes, do campo e da cidade.

As DCNEM e o PNFEN configuram-se como uma oportunidade histórica de redução da desigualdade educacional e de promoção da formação dos jovens na lógica de uma educação para além do capital (MÉSZÁROS, 2008). Porém, há que se atentar para os problemas estruturais, internos e externos à escola - condiçóes de trabalho pedagógico, formação dos profissionais da educação, melhoria das condiçôes de vida dos jovens e suas famílias, etc. — no sentido de buscar formas de superá-los, de romper com a dualidade entre ensino propedêutico e formação profissional, entre conhecimento geral e específico, e avançarmos ainda mais nas proposiçóes do currículo integrado e da formação integral no ensino médio.

\section{REFERÊNCIAS}

BRASIL. Decreto n. 21.241, de 04 de abril de 1932. Consolida as disposiçóes sobre a organização do ensino secundário e dá outras providências. Diário Oficial da União, Brasília, DF, p. 6666, 09 abr. 1932.

. Lei n. 5.692, de 11 de agosto de 1971. Fixa Diretrizes e Bases para o ensino de $1^{\circ}$ e $2^{\circ}$ graus, e dá outras providências. Diário Oficial da União, Brasília, DF, p. 6377, 12 ago. 1971. Seção 1.

. Ministério da Educação. Documento Básico 2000: exame nacional do ensino médio. Brasília: MEC/INEP, 2000.

. Resolução n. 4, de 13 de julho de 2010. Define Diretrizes Curriculares Nacionais Gerais para a Educação Básica. Diário Oficial da União, Brasília, DF, p. 824,14 jul. 2010. Seção 1.

Resolução n. 2, de 30 de janeiro de 2012a. Define Diretrizes Curriculares Nacionais para o ensino Médio. Diário Oficial da União, Brasília, DF, p. 20, 31 jan. 2012. Seção 1. 
. Resolução n. 6, de 20 de setembro de 2012b. Define Diretrizes Curriculares Nacionais para a Educação Profissional Técnica de Nível Médio. Diário Oficial da União, Brasília, DF, p. 22, 21 set. 2012. Seção 1.

. Formação de professores do ensino médio, etapa I - caderno VI: avaliação no ensino médio. Curitiba: UFPR/Setor de Educação, 2013 a.

Formação de professores do ensino médio, etapa I - caderno III: o currículo do ensino médio, seus sujeitos e o desafio da formação humana integral. Curitiba: UFPR/Setor de Educação, 2013b.

- Pacto nacional pela alfabetização na idade certa. Documento orientador das açôes de formação em 2014. Brasília: Ministério da Educação, 2014. Disponível em: <http://pacto.mec.gov.br/images/pdf/Formacao/ documento_orientador_2014_versao_site.pdf>. Acesso: em 05 out. 2015.

CASTRO, E.G. Juventude rural no Brasil: processos de exclusão e a construção de um ator político. Revista Latinoamericana de Ciências Sociales, Niñez y Juventud, v. 7, n. 1, p. 179-208, jan. 2009.

CUNHA, L.A. O ensino profissional na irradiação do industrialismo. 2. ed. São Paulo: Editora UNESP, 2005.

DAYRELL, J. A música entra em cena: o funk e o rap na socialização da juventude em Belo Horizonte. Belo Horizonte: Editora UFMG, 2005.

ENGUITA, M.F. A face oculta da escola: educação e trabalho no capitalismo. Porto Alegre: Artes Médicas, 1989.

FERNANDES, C.; FREITAS, L.C. Indagaçôes sobre currículo: currículo e avaliação. Brasília: Ministério da Educação, 2008.

FRIGOTTO, G.; CIAVATTA, M.; RAMOS, M. Ensino médio integrado: concepçôes e contradiçóes. São Paulo: Cortez, 2005.

KRAWCZYK, N. Reflexão sobre alguns desafios do ensino médio no brasil hoje. Cadernos de Pesquisa, v. 41, n. 144, p. 752-769, set./dez. 2011.

KUENZER, A. Ensino médio: construindo uma proposta para os que vivem do trabalho. 6. ed. São Paulo: Cortez, 2009.

MANACORDA, M.A. Marx e a pedagogia moderna. 2. ed. Campinas: Alínea, 2010. MÉSZÁROS, I. A educação para além do capital. 2. ed. São Paulo: Boitempo, 2008.

MORAES, C.S.V.; ALAVARSE, O.M. Ensino médio: possibilidades de avaliação. Educação e sociedade, Campinas, v. 32, n. 116, p. 807-838, jul./set. 2011. 
PISTRAK, M. Fundamentos da escola do trabalho. São Paulo: Expressão popular, 2001.

RAMOS, M. O projeto unitário de ensino médio sob os princípios do trabalho, da ciência e da cultura. In: MATO GROSSO. Secretaria de Estado de Educação. Currículo e avaliação no ensino médio. Cuiabá: Tanta Tinta, 2004.

RIBEIRO, A.S.; PÁTARO, R.F. Pacto nacional pelo fortalecimento do ensino médio: questôes para o debate. Revista Educação e Linguagens, Campo Mourão, v. 3, n. 4, p. 9-23, jan./jun. 2014.

ROMANELLI, O.O. História da educação no Brasil. 35. ed. Petrópolis: Vozes, 2010.

SILVA, M.R. Currículo e competências: a formação administrada. São Paulo: Cortez, 2008.

SPÓSITO, M.P. Transversalidades no estudo sobre jovens no Brasil: educação, ação coletiva e cultura. Educação e Pesquisa, São Paulo, v. 36, n. especial, p. 95-106, 2010.

\section{NOTAS}

1. O Pacto Nacional pelo Fortalecimento do Ensino Médio foi regulamentado pela Portaria Ministerial n. 1.140, de 22 de novembro de 2013. Por meio dele, o Ministério da Educação e as secretarias estaduais de educação assumem compromisso com a valorização da formação continuada dos professores e coordenadores pedagógicos do ensino médio público, em áreas rurais e urbanas.

Recebido em 07 de abril de 2016

Aceito em 22 de agosto de 2016. 